\section{The Europhysics News}

\section{challenge}

\author{
Claude Sébenne \\ Claude.Sebenne@lmcp.jussieu.fr \\ IMPMC, Campus Boucicaut, Univ. P. et M. Curie, \\ 140 rue de Lourmel, F-75015, Paris
}

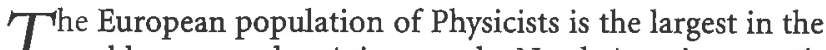
1 world, compared to Asia or to the North American continent. In spite of its size, this population has developed the feeling, during the last 50 years, that it constitutes a single community, certainly in parallel with the impressive political evolution towards unity that Europe has known along the same period. This is of course also true for Mathematics, Chemistry... The need for federal structures came up early and our fathers created the European Physical Society in September 1968. They had to involve the venerable and powerful National Societies: it was out of the question to replace them. Their role remains essential, even if only considering the variety of languages and of educational systems that they represent. However, a pure federation of National Societies was unacceptable and individual physicists or organisations had also to be recognised as members. This delicate balance was struck from the beginning and continues to this day. However, the consequence was to condemn EPS to remain relatively hardpressed financially in spite of the large population of European physicists, simply because its financial needs came second to those of the National Societies.
\end{abstract}

Now, let us come to the EPN challenge. Among its duties, a structure such as EPS has to insure the diffusion of information within its population of physicists. The organisation of conferences and the sponsorship of journals are evident ways but the circulation of its own journal is essential as well. How else to communicate to members the recent progress and new questions in physics research and education, the highlights of recent European events and the purposes of forthcoming ones, the openings in teaching or research positions, the new instruments and machines and so forth, without it? So EPS needs a consistent and well-documented journal, interesting and useful to its members in addition to their National Society journals and, last but not the least, operating on only a small budget. This challenge has been successfully sustained over the years and I am sure that the readers of Europhysics News have appreciated the content and the presentation of the past issues.

Some changes are planned, however, starting from the next issue (36/5:September-October 2005). Most of you will have certainly noticed, when looking at the top of the fourth page of each EPN issue, how small is the team in charge of the practical preparation of the Journal. Presently everything rests on the shoulders of the Science Editor for the content and the Designer for the presentation. In more detail, the Science Editor has not only to interact with authors to obtain their papers, most often after he has required corrections, but also to package on time all the material, including EPS news, for each issue. This is a heavy job bringing maximum stress six times a year and no one should be expected to do it alone for long. The Executive Committee of EPS has recognized the achieve- ments, even under pressure, of the present Science Editor, George Morrison, and has decided to lighten his workload by adding a new person to the EPN team. This new person, who happens to be the author of the present editorial, is expected to take on the position of an overarching Editor. The charge will be to call for and to collect on time all the material needed for each issue and to take it on to the publishers, freeing the Science Editor from the second part of his present tasks. The present Editor, whose primary job is that of Secretary General of EPS, will then become Executive Editor. The enlarged team will now have to show that it can still improve EPN without a budget increase! -

Now, let me answer a few questions that you may have.

\section{Q: What will change in EPN?}

A: Wait and see! The time constant for the content is something like $5 \pm 3$ months, so...

\section{Q: Who is the person that EPS has appointed?}

A: A semiconductor surface physicist, he was Head of the Solid State Physics Laboratory at Université Pierre et Marie Curie, Paris (1986-96)

\section{Q: What are his credentials regarding EPS?}

A: He was Vice Secretary of the Executive Committee (1994-98) then elected representative of IOMs at the Council (2001-03).

\section{Q: And regarding EPN?}

A: Presently a member of the EPN Editorial Advisory Board, he has completed in March 2005 a term of 8 years as Editor of the French Physical Society Bulletin.

Q: How old is he?

A: Old enough for the job.

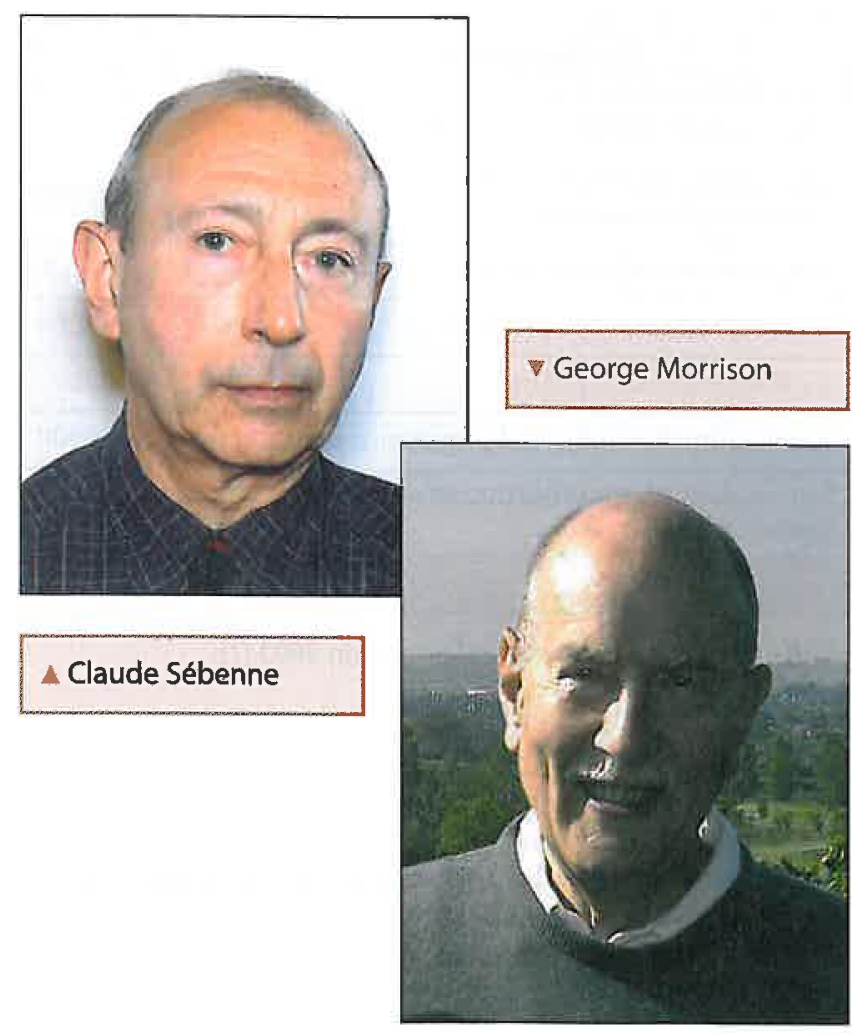

